\title{
Blood pressure and associated factors in a North African adolescent population. a national cross-sectional study in Tunisia
}

\author{
Hajer Aounallah-Skhiri ${ }^{1}{ }^{*}$, Jalila El Ati ${ }^{3}$, Pierre Traissac ${ }^{4}$, Habiba Ben Romdhane ${ }^{1}$, Sabrina Eymard-Duvernay ${ }^{4}$, \\ Francis Delpeuch ${ }^{4}$, Noureddine Achour ${ }^{1}$ and Bernard Maire ${ }^{4}$
}

\begin{abstract}
Background: In southern and eastern Mediterranean countries, changes in lifestyle and the increasing prevalence of excess weight in childhood are risk factors for high blood pressure (BP) during adolescence and adulthood. The aim of this study was to evaluate the BP status of Tunisian adolescents and to identify associated factors.

Methods: A cross-sectional study in 2005, based on a national, stratified, random cluster sample of 1294 boys and 1576 girls aged 15-19 surveyed in home visits. The socio-economic and behavioral characteristics of the adolescents were recorded. Overweight/obesity were assessed by Body Mass Index (BMI) from measured height and weight (WHO, 2007), abdominal obesity by waist circumference (WC). BP was measured twice during the same visit. Elevated BP was systolic (SBP) or diastolic blood pressure (DBP) $\geq 90$ th of the international reference or $\geq 120 /$ $80 \mathrm{~mm} \mathrm{Hg}$ for 15-17 y., and SBP/DBP $\geq 120 / 80 \mathrm{~mm} \mathrm{Hg}$ for 18-19 $y$; hypertension was SBP/DBP $\geq$ 95th for 15-17 $\mathrm{y}$. and $\geq 140 / 90 \mathrm{~mm} \mathrm{Hg}$ for 18-19 y. Adjusted associations were assessed by logistic regression.
\end{abstract}

Results: The prevalence of elevated BP was 35.1\%[32.9-37.4]: higher among boys (46.1\% vs. 33.3\%; $P<0.0001) ; 4.7 \%$ [3.8-5.9] of adolescents had hypertension. Associations adjusted for all covariates showed independent relationships with BMI and WC: - obesity vs. no excess weight increased elevated BP (boys $\mathrm{OR}=2.1[1.0-4.2]$, girls $\mathrm{OR}=2.3[1.3-3.9]$ ) and hypertension (boys $\mathrm{OR}=3.5[1.4-8.9]$, girls $\mathrm{OR}=5.4[2.2-13.4]$ ), - abdominal obesity (WC) was also associated with elevated $\mathrm{BP}$ in both genders (for boys: $2 \mathrm{nd}$ vs. 1st tertile $\mathrm{OR}=1.7[1.3-2.3]$, 3rd vs.1st tertile $\mathrm{OR}=2.8[1.9-4.2]$; for girls: $2 \mathrm{nd}$ vs. 1st tertile $O R=1.6[1.2-2.1]$, 3rd vs.1st tertile $O R=2.1[1.5-3.0]$ ) but only among boys for hypertension. Associations with other covariates were weaker: for boys, hypertension increased somewhat with sedentary lifestyle, while elevated BP was slightly more prevalent among urban girls and those not attending school.

Conclusion: Within the limits of BP measurement on one visit only, these results suggest that Tunisian adolescents of both genders are likely not spared from early elevated BP. Though further assessment is likely needed, the strong association with overweight/obesity observed suggests that interventions aimed at changing lifestyles to reduce this main risk factor may also be appropriate for the prevention of elevated BP.

Keywords: Adolescent, Blood pressure, Tunisia, Prevalence, Risk factors

\section{Background}

Hypertension is a major health problem throughout the world because of its high prevalence and its association with increased risk of cardiovascular diseases in the context of the epidemiological transition [1-4]. The presence of elevated blood pressure (BP) at a young age is

\footnotetext{
* Correspondence: hajer.skhiri@rns.tn

${ }^{1}$ National Institute of Public Health (INSP), 5-7 rue El-Khartoum, Tunis, Tunisie Full list of author information is available at the end of the article
}

a predictor of hypertension later in life [5] and it also has been reported that BP in children is associated with the same lifestyle factors as in adults, i.e. dietary habits [6-8], sedentary behaviors $[9,10]$ and obesity [11-13]. Several studies have reported an increase in the prevalence of this disease in children and adolescents in many countries [14-17]. In Tunisia, where a nutritional transition is currently underway, $25.4 \%$ of $35-70$ yearold adults were obese ( $37 \%$ for women vs. $13.3 \%$ for

\section{() Biomed Central}


men), $61.6 \%$ were overweight $(71.1 \%$ for women and $51.7 \%$ for men) [18] and $30.6 \%$ were found to be hypertensive in 2005 [19]; overweight was also prevalent among 15-19 year-old adolescents and affected 19\% of them (17.4\% for boys and $20.7 \%$ for girls) [20]. However, up to now, no study has attempted to assess the extent of elevated BP at a large scale among Tunisian adolescents. In the context of increasing prevalence of obesity in Tunisia, the aim of this study was to assess BP status in male and female Tunisian adolescents, aged 15-19 years, and to investigate environmental, anthropometric, socio-economic and behavioral (physical activity, perceived stress) associated factors.

\section{Methods}

\section{Study area}

Tunisia is a North African country of about ten million inhabitants [21], that has undergone a steady and rapid economic development and reached an upper middle level of development (ranked 89th out of 177 countries on the Human Development Index composite scale in 2005) [22], but which 7 administrative regions are geographically and socio-economically contrasted.

\section{Study design and subjects}

The national cross-sectional survey of adolescents aged 15 to 19 years was carried out from April to September, 2005. Based on the most recent population census in 2004, the two-stage random clustered sample of households was stratified according to the seven administrative regions of Tunisia. Next, 47 census districts were randomly selected in each region, with a probability proportional to size in number of households. At the second stage, 20 households were sampled randomly in each selected district and all 15-19-year olds living in these households (6580) at the time of the survey were eligible [20]. With reference to the 0.48 ratio of $15-19$ year olds per household (2004 Tunisian census), about 3138 subjects were thus expected to be included.

\section{Data collection and measurements}

Data on demographic characteristics, area (rural vs. urban), household economic status, whether the adolescent was registered at school or not at the time of the survey, low physical activity, and perceived stress were collected using interviewer-administrated questionnaires.

Trained investigators took anthropometric and blood pressure (BP) measurements using standardized procedures.

A household economic score was computed by correspondence analysis from the matrix of binary variables coding for type of house, number of people per room, type of sanitation, type of drinking water supply and possessions such as car, television, computer, satellite dish and refrigerator. This score is the coordinate on the first axis of the correspondence analysis and used as a proxy indicator of the economic level of the household. We identified three levels by dividing the score into tertiles of increasing economic level [23,24].

Adolescents were categorized according to whether they were attending school or not at the time of the survey.

Physical activity practised during the month preceding the survey was estimated using a validated frequency questionnaire $[20,25]$. The international compendium of physical activities was used for the calculation of the metabolic equivalent (MET) of each daily activity [26]. The intensity of the physical activities was classified as light, moderate or vigorous (respectively $<3,3-6$ and $>$ 6 Mets; $1 \mathrm{Met}=3.5 \mathrm{~mL} \mathrm{O}^{2} / \mathrm{kg}$ ) using the CDC-American College of Sports Medicine classification [27]. The percentage of low intensity daytime physical activities was computed and coded into tertiles, with sedentary lifestyle increasing from the 1st to the 3rd tertile.

The perceived stress score was calculated using a validated stress scale composed of four questions [28]. Each question had five answers coded from 0 to 100 . The perceived stress score is the arithmetic mean of the four sub-scores; it increases with the level of perceived stress. For analysis purposes the score was divided in three tertiles of increasing stress level.

\section{Anthropometry}

Weight was measured to the nearest $0.1 \mathrm{~kg}$ using electronic scales (Teraillon, France) with regular checks for accuracy and precision. Height was measured to the nearest millimetre using portable gauges (Seca, Germany), with the subject in a standing position, without shoes. Abdominal fat was assessed by waist circumference (WC) that was measured to the nearest $0.1 \mathrm{~cm}$ using a non-elastic metric measuring tape. Assessment of overweight status was based on the age and sex-specific body mass index (BMI, $\mathrm{kg} / \mathrm{m}^{2}$ ) reference distributions developed by the World Health Organisation [29]. The cut-offs were BMI $\leq+1$ standard deviation $(\mathrm{SD})$ for "no excess weight"; "+1 SD $<$ BMI $\leq+2$ SD" for overweight (but not obese) and BMI $>+2$ SD for obesity. WC was coded in tertiles (separately for each gender).

\section{Blood pressure}

BP was measured twice by the auscultatory method using a stethoscope and calibrated sphygmomanometers (Vaquez Laubry type, Spengler, France): the first measurement after $10 \mathrm{~min}$ of rest and the second at the end of the interview (an average of $30 \mathrm{~min}$ later). The estimation of BP was based on the average of the two measurements. For 15-17 year olds, pre-hypertension (preHT) was defined as average systolic BP (SBP) and/or diastolic BP (DBP) $\geq 90$ th age, sex and height specific percentile (or $\geq 120 / 80 \mathrm{~mm} \mathrm{Hg}$ ) but $<95$ th percentile; 
hypertension (HT) as average SBP and/or DBP levels $\geq$ 95th percentile of the reference values for age, sex and height according to the standard definition introduced in 2003 and extended to children and adolescents in 2004 [30]. For 18-19 year olds, pre-HT was defined as average SBP/DBP $\geq 120 / 80 \mathrm{~mm} \mathrm{Hg}$ but $<140 / 90 \mathrm{~mm}$ $\mathrm{Hg}$; $\mathrm{HT}$ as $\mathrm{SBP} / \mathrm{DBP} \geq 140 / 90 \mathrm{~mm} \mathrm{Hg}[31,32]$. Hence, we defined elevated $\mathrm{BP}$ as SBP/DBP $\geq 90$ th percentile (or above $120 / 80 \mathrm{~mm} \mathrm{Hg}$ ).

\section{Ethics}

The protocol of the survey was reviewed and approved by the Ethics Committee on Human Research of the National Institute of Nutrition and the Tunisian National Council of Statistics (visa ${ }^{\circ} 5 / 2005$ ). Subjects were informed of their right to refuse and of the strict respect of the confidentiality of their answers. All adolescents and their parents gave their verbal consent.

\section{Data management and statistical analysis}

Epidata software, version 3.1 was used for data entry and validation [33] and Stata 11 for data management and analysis [34]. The type I error risk was set at 0.05 . All analyses (descriptive, crude and adjusted associations) took the sampling design (stratification, clustering and sampling weights) into account.

Due to gender differences underlined in preliminary analyses, all analyses were performed separately for each gender. Descriptive analysis of the sample including demographic, socio- economic, anthropometric and BP characteristics was performed using t-tests to compare means and chi-square tests to compare percentages between genders. We studied unadjusted associations between socio-demographic, lifestyle factors and anthropometric status and blood pressure status (prevalence of elevated BP and HT) using chi-square tests. Local polynomial smoothing was used to graphically assess the unadjusted relationship between BMI and WC and elevated $\mathrm{BP}$ and hypertension by gender.

Multivariate logistic regression models were fitted to assess adjusted associations between covariates and elevated BP or hypertension: covariates were age (interval), area (urban vs. rural), household economic level (in tertiles), school status (attending school vs. not), percentage of low intensity daily physical activity (in tertiles), perceived stress score (in tertiles), BMI (no excess weight/overweight/obesity), WC (tertiles by gender). We first fitted separate models to assess association of BMI (respectively WC) with BP separately (adjusting for age and all socioeconomic and behavioral characteristics). In the second step, we performed the analyses using both WC and BMI simultaneously in the models.

\section{Results}

\section{Sample characteristics}

Taking into account refusals, absences and missing BP data, 2870 out of the expected 3138 15-19-year old subjects were used in the analyses i.e. an overall response rate of $91.5 \%$.

Socio-demographic characteristics, lifestyle factors, anthropometric and BP status for boys and girls are shown in Table 1. The weighted estimate of the proportion of females was $49 \%$ but there was nonetheless a substantially lower response rate for males. About two thirds of the adolescents lived in urban areas. One third of the adolescents were not attending school during the study period with a higher percentage of boys. The household economic level was similar among boys and girls. Compared to boys, girls had a more sedentary lifestyle and higher level of perceived stress. Mean BMI $\left(\mathrm{kg} / \mathrm{m}^{2}\right)$ was higher for females $(22.0 \pm 0.1)$ than for males $(20.9 \pm 0.1)$. The prevalence of overweight (not including obesity) among adolescents was $20.1 \% \pm 1.0$ and obesity prevalence was $5.0 \% \pm 0.6$ with no statistically significant difference between boys and girls. Mean waist circumference $(\mathrm{cm})$ was $75.7 \pm 0.4$ for boys and $73.1 \pm 0.3$ for girls. The mean systolic and diastolic BP $(\mathrm{mmHg})$ was higher in males: the mean SBP was 114.2 \pm 0.4 for boys and $110.9 \pm 0.4$ for girls $(P<0.0001)$ and the mean DBP was $68.1 \pm 0.3$ for boys and $66.6 \pm 0.4$ for girls $(P<0.001)$. The prevalence of elevated BP was $39.8 \%$ [37.4-42.3], higher among boys (46.1\% [42.7-49.5]) than among girls $(33.3 \%$ [30.0-36.7]; $P<0.0001)$. One third of the adolescents had a pre-HT (35.1\% [32.9$37.4]$ ), and pre-HT was more frequent among boys (41.8\% [38.5-45.1]) than girls $(28.2 \%$ [25.2-31.4]; $P<$ 0.0001). HT was present in 4.7\% [3.8-5.9] of adolescents with no significant difference between boys and girls.

\section{Univariate analysis}

For both genders, the prevalence of elevated BP increased quite linearly with BMI $(P<0.0001)$, the association being somewhat steeper for boys (Figure 1); a significant association was also found with WC for both genders $(P<0.0001)$. Association of BMI and WC with hypertension was also marked for both genders, these associations being stronger after the 50th centile of BMI and especially for WC (Figure 1). In accordance, prevalence of elevated BP and HT increased markedly with BMI categories; a similar association was found for elevated $\mathrm{BP}$ with WC tertiles but the prevalence of HT only increased in the third tercile of WC (vs. 1st and 2nd tertiles, Table 2). Relationship between BMI and WC was obviously strong for both genders as the linear correlation coefficient was $0.72(P<0.0001)$ for boys and $0.66(P<0.0001)$ for girls. 
Table 1 Characteristics of the sample of 15-19 y, Tunisian adolescents $(n=2870)$.

\begin{tabular}{|c|c|c|c|c|c|}
\hline \multirow{3}{*}{ Characteristics } & \multicolumn{3}{|c|}{ Boys } & \multirow{2}{*}{$\begin{array}{c}\text { Girls } \\
\text { Mean(s.e.) } \\
\text { or } \\
\%^{2}\end{array}$} & \multirow[b]{2}{*}{$\begin{array}{c}P- \\
\text { value }\end{array}$} \\
\hline & $\mathrm{n}^{1}$ & $\begin{array}{c}\text { Mean(s.e.) } \\
\text { or } \\
\%^{2} \\
\end{array}$ & $\mathrm{n}^{1}$ & & \\
\hline & 1294 & 51.0 & 1576 & 49.0 & \\
\hline \multicolumn{6}{|l|}{ Age (years) } \\
\hline $15-17$ & 838 & 63.2 & 982 & 63.2 & 0.99 \\
\hline $18-19$ & 456 & 36.8 & 594 & 36.8 & \\
\hline \multicolumn{6}{|l|}{ Area } \\
\hline Urban & 707 & 62.3 & 825 & 62.4 & 0.93 \\
\hline Rural & 587 & 37.7 & 751 & 37.6 & \\
\hline \multicolumn{6}{|l|}{ Socio-economic factors } \\
\hline \multicolumn{6}{|l|}{ Household's economic level } \\
\hline Low & 526 & 38.4 & 645 & 37.4 & \\
\hline Intermediate & 427 & 32.1 & 552 & 36.0 & 0.14 \\
\hline High & 283 & 29.5 & 299 & 26.6 & \\
\hline Attending school & 1292 & 69.1 & 1572 & 74.2 & 0.020 \\
\hline \multicolumn{6}{|l|}{ Behavioral factors } \\
\hline \multicolumn{6}{|c|}{ Proportion of low physical activity } \\
\hline $\begin{array}{l}7^{\text {st }} \text { tertile } \\
\text { (low) }\end{array}$ & 562 & 46.2 & 283 & 20.0 & \\
\hline $\begin{array}{l}2^{\text {nd }} \text { tertile } \\
\text { (middle) }\end{array}$ & 413 & 31.0 & 543 & 35.8 & $<10^{-4}$ \\
\hline $\begin{array}{l}3^{\text {rd }} \text { tertile } \\
\text { (high) }\end{array}$ & 319 & 22.8 & 750 & 44.3 & \\
\hline \multicolumn{6}{|l|}{ Perceived stress } \\
\hline $\begin{array}{l}1^{\text {st }} \text { tertile } \\
\text { (low) }\end{array}$ & 473 & 37.7 & 504 & 31.6 & \\
\hline $\begin{array}{l}2^{\text {nd }} \text { tertile } \\
\text { (middle) }\end{array}$ & 474 & 35.9 & 566 & 36.0 & 0.0021 \\
\hline $\begin{array}{l}3^{r d} \text { tertile } \\
\text { (high) }\end{array}$ & 341 & 26.4 & 500 & 32.4 & \\
\hline \multicolumn{6}{|c|}{ Anthropometric characteristics } \\
\hline Body Mass Index $\left(\mathrm{kg} / \mathrm{m}^{2}\right)$ & 1294 & $20.9(0.1)$ & 1576 & $22.0(0.1)$ & $<10^{-4}$ \\
\hline $\begin{array}{l}\text { No excess } \\
\text { weight }\end{array}$ & 1011 & 76.9 & 1161 & 72.9 & \\
\hline Overweight & 218 & 17.9 & 337 & 22.3 & 0.085 \\
\hline Obesity & 65 & 5.2 & 78 & 4.8 & \\
\hline Waist circumference $(\mathrm{cm})$ & 1287 & $75.7(0.4)$ & 1571 & $73.1(0.3)$ & $<10^{-4}$ \\
\hline $1^{\text {st }}$ tertile & 496 & 33.4 & 632 & 36.7 & \\
\hline $2^{\text {nd }}$ tertile & 433 & 35.3 & 468 & 31.7 & 0.14 \\
\hline $3^{\text {rd }}$ tertile & 358 & 31.3 & 471 & 31.7 & \\
\hline \multicolumn{6}{|l|}{ Blood pressure (BP) status } \\
\hline Systolic BP (mmHg) & 1294 & $114.2(0.4)$ & 1576 & $110.9(0.4)$ & $<10^{-4}$ \\
\hline Diastolic BP (mmHg) & 1294 & $68.1(0.3)$ & 1576 & $66.6(0.4)$ & $<10^{-3}$ \\
\hline Elevated BP & 1294 & 46.1 & 1576 & 33.3 & $<10^{-4}$ \\
\hline Hypertension & 1294 & 4.3 & 1576 & 5.1 & 0.45 \\
\hline
\end{tabular}

1-Number of subjects surveyed

2-Weighted mean (standard error) or proportion (accounting for unequal probabilities of selection and/or differential response rates)

3 - Boys vs. girls (chi-square test for $\%, t$-test for means)
Regarding crude associations with socio-demographic and lifestyle factors, for boys, the prevalence of HT increased with tertiles of low daily physical activity (Table 2). For girls, the prevalence of elevated BP and HT was higher in rural than urban settings, and among those who were not attending school. Prevalence of elevated BP decreased somewhat with higher household economic levels (Table 2).

\section{Multivariate analysis}

In analyses (detailed data not shown), adjusted for all socio-economic and behavioral covariates but including only one anthropometric index at a time, obesity vs. no excess weight markedly increased the prevalence of HT (boys $\mathrm{OR}=8.4[3.7-18.8]$, girls $\mathrm{OR}=7.2[3.2-16.1] ; P<$ $10^{-4}$ ) and that of elevated BP (boys OR $=3.7[2.0-6.9]$, girls $\left.\mathrm{OR}=3.4[2.1-5.6] ; P<10^{-4}\right)$; similar though weaker associations were observed with overweight. WC was also associated with elevated BP in both genders (for boys: 2 nd tertile vs. 1 st tertile $\mathrm{OR}=1.7[1.3-2.4]$, 3rd tertile vs.1st tertile $\mathrm{OR}=4.0[2.9-5.5] P<10^{-4}$; for girls: 2 nd tertile vs. 1st tertile $\mathrm{OR}=1.7[1.2-2.2]$, 3rd tertile vs.1st tertile $\mathrm{OR}=2.8[2.0-3.8] P<10^{-4}$ ); a similar but weaker association was observed with HT for boys and girls.

In adjusted analyses including simultaneously BMI and WC in the models (Table 3), the strength of the association with BMI and WC decreased somewhat: but being obese vs. having no excess weight still markedly increased HT (boys OR $=3.5[1.4-8.9]$, girls $\mathrm{OR}=5.4$ [2.2-13.4]) as well as elevated BP (boys OR $=2.1[1.0$ $4.2]$, girls $\mathrm{OR}=2.3[1.3-3.9]$ ); analogous though weaker associations were observed with overweight. WC was also still associated with elevated BP in both sexes (for boys: 2 nd tertile vs. 1 st tertile $\mathrm{OR}=1.7[1.3-2.3]$, 3rd tertile vs.1st tertile $\mathrm{OR}=2.8[1.9-4.2]$; for girls: 2 nd tertile vs. 1 st tertile $\mathrm{OR}=1.6[1.2-2.1]$, 3rd tertile vs.1st tertile $\mathrm{OR}=2.1[1.5-3.0])$; a similar but weaker association was observed with HT in boys only. Adjusted associations with socio-economic and behavioral covariates were less straightforward and varied by gender: for boys, HT somewhat increased with sedentary lifetsyle (medium tertile vs. low $\mathrm{OR}=2.3[1.0-4.9]$, high vs. low $\mathrm{OR}=2.8$ [1.1-7.0]), for girls elevated BP was slightly more prevalent in urban settings (urban vs. rural OR $=1.5[1.1-2.1]$ ) and among those who were not attending school $(\mathrm{OR}=$ $1.4[1.0-1.8]$ ) or had a more sedentary lifestyle (high vs. low $\mathrm{OR}=1.4[1.0-1.9])$.

\section{Discussion}

The main results of this national study showed that elevated $\mathrm{BP}$ was prevalent among Tunisian adolescents, 


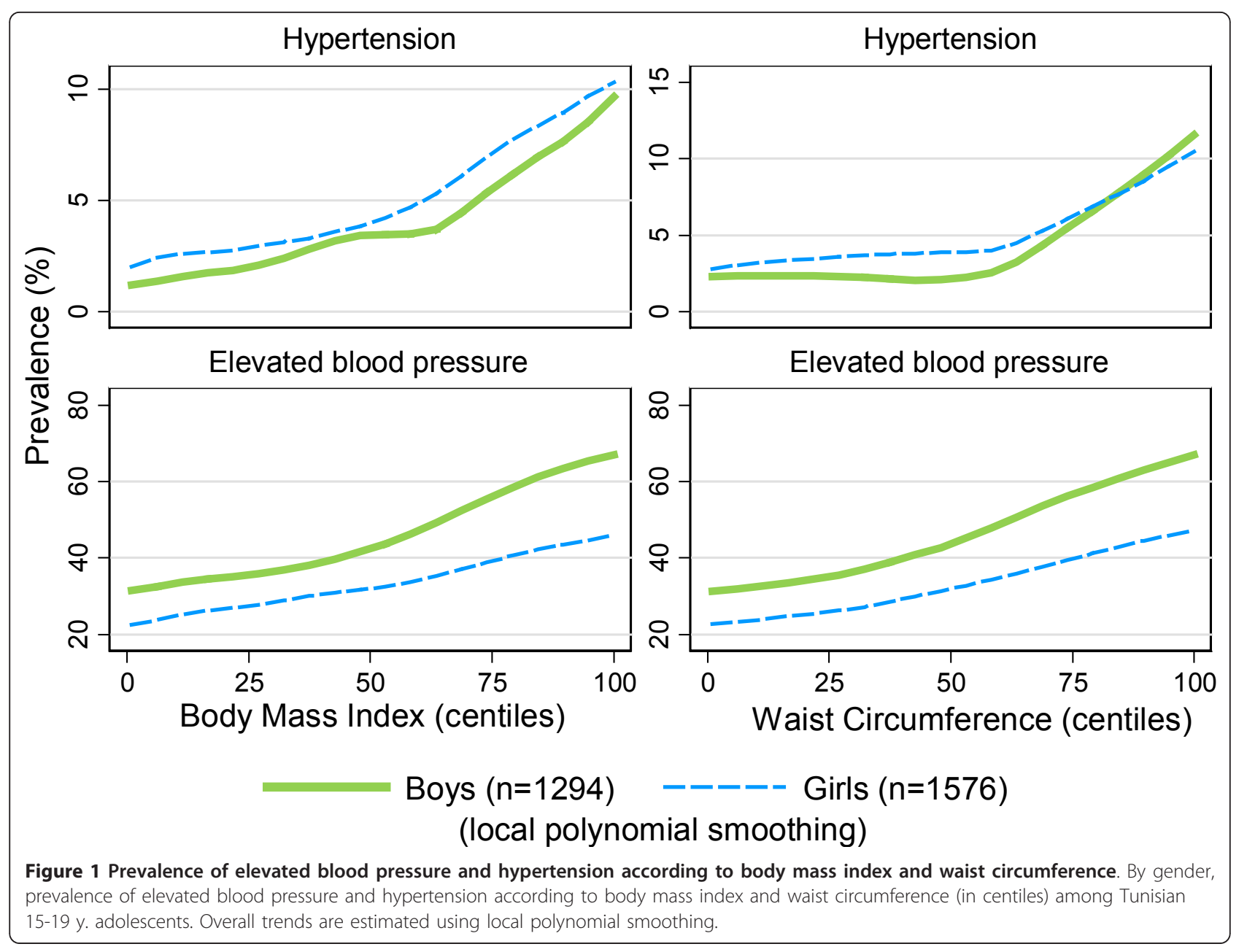

more so in boys, that prevalence increased strongly with BMI and WC, while associations with behavioral and socio-economic factors were much less straightforward.

Apart from a possible overestimation of BP due to methodology limits, the observed prevalence of pre-HT and HT in Tunisian adolescents are among the highest rates reported in the literature for this age class, where prevalence ranged between $<1 \%$ and $5.1 \%$ for $\mathrm{HT}$ $[15,32,35]$ and from $<10 \%$ to $<40 \%$ for pre-HT [32,36-39]. Comparing the prevalence of elevated BP with data in the literature is difficult because it is easily subject to bias related to the class of age chosen as well as regional differences in the definition of elevated BP, the distribution of reference BP data and the method used to measure BP $[31,32,40]$. However in many countries, it remains largely underestimated [41,42]. Recently, Hansen et al. [42] showed that among a cohort of 14187 children and adolescents aged 3-18 followed regularly in a large academic urban medical system in northeast Ohio (USA), only $26 \%$ of HT and $11 \%$ of pre-HT cases had an appropriate diagnosis recorded in their electronic medical record. The authors suggested that this low diagnosis rate could be accounted for by the lack of knowledge concerning normal BP ranges and the lack of awareness of a patient's previous BP readings. Thus, it would be useful to provide a practical tool for physicians to enable them to easily identify the threshold of normal $\mathrm{BP}$ values for adolescents according to age, gender and height.

The present study identified gender differences mainly in the prevalence of elevated BP as Tunisian males were more affected than females. Gender differences in the risk of developing elevated $\mathrm{BP}$ have been reported by several authors in different populations [37,43-45]. According to Dasgupta et al., the gender differences in the risk of elevated BP can be explained by the impact of sex steroids on BP [44]. This factor is also strongly suggested by experimental models [46].

The prevalence of elevated BP and HT were higher among overweight and obese Tunisian adolescents. The association between BP level and overweight status has been documented in many young populations thanks to 
Table 2 Unadjusted associations of socio-demographic and lifestyle factors, Body Mass Index and Waist Circumference with blood pressure

\begin{tabular}{|c|c|c|c|c|c|c|c|c|c|c|}
\hline & \multicolumn{6}{|c|}{ Boys } & \multicolumn{4}{|c|}{ Girls } \\
\hline & \multicolumn{3}{|c|}{ Elevated $\mathrm{BP}^{1}$} & \multicolumn{3}{|c|}{ Hypertension } & \multicolumn{2}{|c|}{ Elevated $\mathrm{BP}^{1}$} & \multicolumn{2}{|c|}{ Hypertension } \\
\hline & $\mathbf{n}$ & $\%^{2}$ & $\mathrm{P}^{3}$ & $\%^{2}$ & $\mathrm{P}^{3}$ & $\mathbf{n}$ & $\%^{2}$ & $\mathrm{P}^{3}$ & $\%^{2}$ & $\mathrm{P}^{3}$ \\
\hline \multicolumn{11}{|l|}{ Area } \\
\hline Urban & 707 & 46.6 & 0.69 & 4.4 & 0.90 & 825 & 29.0 & 0.0010 & 3.8 & 0.011 \\
\hline Rural & 587 & 45.2 & & 4.2 & & 751 & 40.4 & & 7.3 & \\
\hline \multicolumn{11}{|c|}{ Household's economic level } \\
\hline Low & 526 & 45.6 & & 3.0 & & 645 & 37.9 & & 6.5 & \\
\hline Intermediate & 427 & 44.0 & 0.44 & 4.2 & 0.35 & 552 & 33.2 & 0.037 & 4.5 & 0.068 \\
\hline High & 283 & 49.5 & & 5.5 & & 299 & 27.4 & & 2.6 & \\
\hline \multicolumn{11}{|l|}{ Attending school } \\
\hline Yes & 893 & 44.1 & 0.079 & 4.2 & 0.73 & 1151 & 30.6 & 0.0012 & 4.1 & 0.003 \\
\hline No & 399 & 50.8 & & 4.7 & & 421 & 41.2 & & 8.3 & \\
\hline \multicolumn{11}{|c|}{ Proportion of low physical activity } \\
\hline $1^{\text {st }}$ tertile (low) & 562 & 44.5 & & 2.3 & & 283 & 30.3 & & 5.6 & \\
\hline $2^{\text {nd }}$ tertile (middle) & 413 & 46.3 & 0.56 & 5.0 & 0.0096 & 543 & 31.6 & 0.18 & 3.6 & 0.13 \\
\hline $3^{\text {rd }}$ tertile (high) & 319 & 49.0 & & 7.4 & & 750 & 36.0 & & 6.1 & \\
\hline \multicolumn{11}{|l|}{ Perceived stress } \\
\hline $1^{\text {st }}$ tertile (low) & 473 & 44.6 & & 4.0 & & 504 & 33.3 & & 5.8 & \\
\hline $2^{\text {nd }}$ tertile (middle) & 474 & 47.0 & 0.82 & 5.6 & 0.30 & 566 & 35.8 & 0.33 & 3.8 & 0.25 \\
\hline $3^{\text {rd }}$ tertile (high) & 341 & 46.1 & & 3.0 & & 500 & 30.6 & & 5.9 & \\
\hline \multicolumn{11}{|l|}{ Body Mass Index } \\
\hline No excess weight & 1011 & 39.6 & & 2.7 & & 1161 & 28.9 & & 3.3 & \\
\hline Overweight & 218 & 65.9 & $<10^{-4}$ & 4.8 & $<10^{-4}$ & 337 & 43.5 & $<10^{-4}$ & 8.7 & $<10^{-4}$ \\
\hline Obesity & 65 & 74.4 & & 26.0 & & 78 & 52.8 & & 15.3 & \\
\hline \multicolumn{11}{|l|}{ Waist Circumference } \\
\hline $1^{\text {st }}$ tertile & 496 & 31.6 & & 2.5 & & 632 & 23.8 & & 3.5 & \\
\hline $2^{\text {nd }}$ tertile & 433 & 43.9 & $<10^{-4}$ & 1.4 & $<10^{-4}$ & 468 & 32.6 & $<10^{-4}$ & 3.5 & $<10^{-3}$ \\
\hline $3^{\text {rd }}$ tertile & 358 & 64.1 & & 9.7 & & 471 & 44.8 & & 8.7 & \\
\hline
\end{tabular}

1-Blood Pressure

2-Weighted prevalences (accounting for unequal probabilities of selection and/or differential response rates)

3-P-value for unadjusted association between elevated BP or hypertension and variable in left column

prospective and cross-sectional studies [11,32,47-49]. According to a recent review, there are three main mechanisms of obesity-induced- hypertension: activation of the sympathetic nervous system, renal, and hormonal dysfunction [50].

On the other hand, in the models including both BMI and WC as covariates, a significant association was found between WC and BP status for males and females adolescents, especially with elevated BP. These results show that BMI and WC, despite being strongly correlated, once adjusted for one another, remain significantly associated with elevated BP, indicating that they are independently associated with elevated BP. These findings are in agreement with data in the literature [49,51-53]. Indeed, according to many authors, the distribution of body fat in particular abdominal fat, is even considered to be more predictive of health risk than whole body composition measures such as BMI [54]. The association between $\mathrm{WC}$ and elevated BP has been attributed to hyperinsulinemia induced by excess abdominal fat $[55,56]$.

Comparison (detailed data not shown) of our BP data with data gathered among Tunisian adolescents (aged 15-19) during the Tunisian 1997 national survey using comparable data (1996 BP data featuring only one measurement compared to the first measurement of our 2005 survey), showed that SBP and DBP had decreased in girls but remained stable in boys. Adjustment for BMI, age, height, and area (urban/rural) did not change these trends. BMI is a major determinant of $\mathrm{BP}$, but the absence of an increase in BP over the time in Tunisia and reported in several other studies, suggests that, despite the significant increases in the prevalence of overweight [57], other factors may also have an influence on the evolution of BP [58]. Such factors may include diet characteristics, i.e. the intake of fruits, vegetables, or dairy products, which leads to an increase in calcium consumption, which traditionally was rather 
Table 3 Adjusted associations of socio-demographic and lifestyle factors, Body Mass Index and Waist Circumference with blood pressure

\begin{tabular}{|c|c|c|c|c|c|c|c|c|}
\hline & \multicolumn{4}{|c|}{$\operatorname{Boys}\left(n=1221^{1}\right)$} & \multicolumn{4}{|c|}{ Girls(n=1484 $\left.{ }^{1}\right)$} \\
\hline & \multirow{2}{*}{$\begin{array}{l}\text { Elevated } \mathrm{BP}^{2} \\
\text { Adjusted } \mathrm{OR}^{3} \\
(\mathrm{Cl} 95 \%)\end{array}$} & \multirow[b]{2}{*}{$\mathrm{P}^{4}$} & \multicolumn{2}{|c|}{ Hypertension } & \multicolumn{2}{|c|}{ Elevated $\mathrm{BP}^{2}$} & \multicolumn{2}{|c|}{ Hypertension } \\
\hline & & & $\begin{array}{l}\text { Adjusted } \mathrm{OR}^{3} \\
\text { (CI95\%) }\end{array}$ & $\mathrm{P}^{4}$ & $\begin{array}{l}\text { Adjusted } \mathrm{OR}^{3} \\
\quad(\mathrm{C} 195 \%)\end{array}$ & $\mathrm{P}^{4}$ & $\begin{array}{l}\text { Adjusted } \mathrm{OR}^{3} \\
\text { (CI95\%) }\end{array}$ & $\mathrm{P}^{4}$ \\
\hline \multicolumn{9}{|l|}{ Area } \\
\hline Urban & 1 & 0.49 & 1 & 0.22 & 1 & 0.021 & 1 & 0.081 \\
\hline Rural & $1.1(0.8-1.5)$ & & $1.6(0.8-3.5)$ & & $1.5(1.1-2.1)$ & & $1.6(0.9-2.8)$ & \\
\hline \multicolumn{9}{|c|}{ Household's economic level } \\
\hline Low & 1 & & 1 & & 1 & & 1 & \\
\hline Intermediate & $0.8(0.6-1.1)$ & 0.29 & $1.6(0.7-3.7)$ & 0.27 & $0.9(0.7-1.3)$ & 0.52 & $0.8(0.5-1.5)$ & 0.62 \\
\hline High & $1.0(0.7-1.5)$ & & $2.1(0.8-5.5)$ & & $0.8(0.5-1.2)$ & & $0.6(0.2-1.8)$ & \\
\hline \multicolumn{9}{|l|}{ Attending school } \\
\hline Yes & 1 & 0.065 & 1 & 0.32 & 1 & 0.033 & 1 & 0.088 \\
\hline No & $1.4(1.0-2.0)$ & & $1.5(0.7-3.4)$ & & $1.4(1.0-1.8)$ & & $1.8(0.9-3.5)$ & \\
\hline \multicolumn{9}{|c|}{ Proportion of low physical activity } \\
\hline $1^{\text {st }}$ tertile (low) & 1 & & 1 & & 1 & & 1 & \\
\hline $2^{\text {nd }}$ tertile (middle) & $1.2(0.9-1.6)$ & 0.35 & $2.3(1.0-4.9)$ & 0.072 & $1.1(0.8-1.6)$ & 0.054 & $0.7(0.3-1.4)$ & 0.075 \\
\hline $3^{\text {rd }}$ tertile (high) & $1.3(0.9-1.8)$ & & $2.8(1.1-7.0)$ & & $1.4(1.0-1.9)$ & & $1.4(0.7-2.9)$ & \\
\hline \multicolumn{9}{|l|}{ Perceived stress } \\
\hline $1^{\text {st }}$ tertile (low) & 1 & & 1 & & 1 & & 1 & \\
\hline $2^{\text {nd }}$ tertile (middle) & $1.0(0.7-1.4)$ & 0.88 & $1.1(0.5-2.2)$ & 0.45 & $1.1(0.8-1.6)$ & 0.54 & $0.7(0.3-1.3)$ & 0.25 \\
\hline $3^{\text {rd }}$ tertile (high) & $0.9(0.7-1.3)$ & & $0.7(0.3-1.6)$ & & $1.0(0.7-1.4)$ & & $1.1(0.6-2.0)$ & \\
\hline \multicolumn{9}{|l|}{ Body Mass Index } \\
\hline No excess weight & 1 & & 1 & & 1 & & 1 & \\
\hline Overweight & $2.0(1.3-2.9)$ & 0.0014 & $0.9(0.4-2.4)$ & 0.012 & $1.5(1.1-2.1)$ & 0.0028 & $2.1(1.0-4.3)$ & 0.0017 \\
\hline Obesity & $2.1(1.0-4.2)$ & & $3.5(1.4-8.9)$ & & $2.3(1.3-3.9)$ & & $5.4(2.2-13.4)$ & \\
\hline \multicolumn{9}{|l|}{ Waist circumference } \\
\hline $1^{\text {st }}$ tertile & 1 & & 1 & & 1 & & 1 & \\
\hline $2^{\text {nd }}$ tertile & $1.7(1.3-2.3)$ & $<10^{-4}$ & $0.5(0.2-1.7)$ & 0.0046 & $1.6(1.2-2.1)$ & 0.0001 & $1.0(0.4,2.2)$ & 0.50 \\
\hline $3^{\text {rd }}$ tertile & $2.8(1.9-4.2)$ & & $2.7(1.1-6.6)$ & & $2.1(1.5-3.0)$ & & $1.5(0.7-3.2)$ & \\
\hline
\end{tabular}

1-Complete case analysis

2- Blood pressure

3- OR: Odds-Ratio, adjusted for age and all the variables in the first column

4- Adjusted for age and all the variables in the first column

low; as a matter of fact, increased consumption of dairy products has been repeatedly associated with reduced risk of elevated BP [59-61]. In accordance, the assessment of dietary intake in a subsample of the same subjects [62], underlined a main dietary pattern of modernization associated with urbanization and regional socio-economic development, this pattern being associated with a favorable effect on BP in girls.

According to some authors, studies using uniformly standardized methodology showed a positive trend in the prevalence of HT among adolescents especially with increasing prevalence of obesity, in contrast to other studies which showed a decrease [32]. On the other hand, Chiolero et al. showed that at the population level, a marked increase in the prevalence of obesity in children and adolescents in a rapidly developing country was not associated with a commensurate secular rise in mean BP [58-61,63] despite the strong relationship between obesity and elevated BP at individual level in the same study. On the other hand, some authors showed that obesity during childhood is associated with elevated BP in early adulthood $[64,65]$. All these results lead us to formulate the following hypothesis: persistent exposure to overweight is a risk factor for elevated BP later; the association observed at individual level may be explained by premature exposure to overweight in early childhood and the recent exposure to overweight could expose the subjects to the risk of elevated BP in early adulthood. Hence, the effect of the increase in the prevalence of overweight in Tunisian adolescents will probably lead to an increase in the prevalence of BP later in adulthood.

In our study, elevated BP and/or HT among males and females was not strongly associated with the other 
factors we analyzed (socio-economic factors, physical activity, stress level) as much as with intermediate outcomes such as BMI and WC. Prevalence of elevated BP increased somewhat with an increase in sedentarity level among Tunisian adolescents; this result is consistent with most other studies $[37,44,63,66,67]$. Hence, the promotion of weight control using appropriate strategies (measures that target environmental factors as well as behavioral ones) in Tunisian children and adolescents aimed at reducing overweight, could also help reduce elevated BP and many other risk factors of chronic diseases during adolescence and adulthood. Our data did not reveal any link between perceived stress and BP. Indeed, there is a controversy in the literature about this relationship as some studies based on declared perceived stress report decreasing associations [68-70].

The absence of monitoring of BP among adolescents reflects the facts that the majority of physicians and parents in Tunisia think that elevated BP is rare among adolescents and are probably not aware of current epidemiologic trends in adolescents' health. Indeed, the prevalence of overweight and obesity (risk factors for elevated BP) among adolescents has increased in Tunisia [20], due to the epidemiological transition and its impact on the environment and changes in lifestyle: indeed the analysis of changes in the food consumption behavior among 15-19-year old Tunisian adolescents between 1997 and 2005 showed for instance that the intake of total fat, saturated fat and total sugars increased while the intake of PUFAs decreased [57]. Pre-HT left untreated during adolescence predisposes to persistent HT in adulthood [71]. Thus, it is reasonable to take action to prevent elevated BP during childhood and adolescence and to contribute to reducing morbidity and mortality related mainly to cardiovascular diseases. However, whereas screening should be focused on overweight and obese young people; primary prevention should concern the whole young population.

As for its strengths and limitations, the study was based on a large random sample of the Tunisian adolescents, the first at such a large scale in Tunisia. However, the cross-sectional design has known limitations regarding causal interpretations of observed associations between the measured covariates and elevated BP and HT. For financial and practical reasons, assessment of the BP status, was based on two measurements of BP made during the same visit. Indeed, we measured BP in non-stress conditions (at home, no white coat), and a recent study showed that BP screening based on three or more measurements per visit was no better than two [72], but not using sets of measurements made during repeated visits as advised in the literature [30], may have led to overestimation of elevated BP [15]. Not taking into account dietary habits was another obvious limitation of this study but this aspect had already partly been dealt with by the same authors though only on a sub-sample of the subjects [62].

\section{Conclusion}

Within the limits of the results based on BP measurement on one visit only, our results suggest that Tunisian adolescents of both genders are likely not spared from early elevated BP. Though no clear-cut associations between BP and environmental or behavioral factors were identified in the study and further studies are needed, the strong association with overweight or obesity suggest that interventions aimed at lifestyle modifications to reduce that main risk factor could be also useful in the prevention of HT or elevated BP among Tunisian adolescents and thus reducing the risk of associated diseases when this generation reaches adulthood.

\section{Acknowledgements}

This study was financed by:

- the European Commission as part of the 'TAHINA' research project

(Epidemiological Transition And Health Impact in North Africa, Inco-Med Contract ICA3-CT-2002-10011)

- INSP: National Institute of Public Health, Tunisia.

- IRD: Institut de Recherche pour le Developpement, France.

- UNICEF, Tunisia.

The first author benefited from a training scholarship from the IRD - DSF

Department (Département Soutien et Formation aux communautés

scientifiques du Sud)

The authors are extremely grateful to the personnel of the Regional Health

Directions who were involved in the data collection, and to the participants.

\section{Author details}

${ }^{1}$ National Institute of Public Health (INSP), 5-7 rue El-Khartoum, Tunis, Tunisie. ${ }^{2}$ Doctoral School 393, Université Pierre et Marie Curie, Paris, France. ${ }^{3}$ National Institute of Nutrition and Food Technology (INNTA), 11 rue Jebel Lakhdar, Tunis, Tunisia. ${ }^{4}$ IRD (Institut de Recherche pour le Developpement), UMR 204 NUTRIPASS, IRD-UM2-UM1, 911 av. Agropolis, 34394 Montpellier, France.

\section{Authors' contributions}

HAS designed the study, supervised data collection, planned and performed data analysis and drafted the manuscript; JEA and PT helped interpret the results and write the manuscript; SED helped with data management; HBR and NA contributed to the study design, FD contributed to the study design and to writing the manuscript; and BM was involved in all steps, from the design of the study to the revision of the manuscript. All authors read and approved the manuscript.

\section{Competing interests}

The authors declare that they have no competing interests.

Received: 2 August 2011 Accepted: 3 February 2012

Published: 3 February 2012

\section{References}

1. Mehio Sibai A, Nasreddine L, Mokdad AH, Adra N, Tabet M, Hwalla N: Nutrition transition and cardiovascular disease risk factors in Middle East and North Africa countries: reviewing the evidence. Ann Nutr Metab 2010, 57:193-203.

2. Mittal BV, Singh AK: Hypertension in the developing world: challenges and opportunities. Am J Kidney Dis 2010, 55:590-598.

3. Lee DE, Cooper RS: Recommendations for global hypertension monitoring and prevention. Curr Hypertens Rep 2009, 11:444-449. 
4. Chobanian AV, Bakris GL, Black HR, Cushman WC, Green LA, Izzo JL, Jones DW, Materson BJ, Oparil S, Wright JT Jr, Roccella EJ: The Seventh Report of the Joint National Committee on Prevention, Detection, Evaluation, and Treatment of High Blood Pressure: the JNC 7 report. Jama 2003, 289:2560-2572.

5. Lauer RM, Clarke WR, Mahoney LT, Witt J: Childhood predictors for high adult blood pressure. The Muscatine Study. Pediatr Clin North Am 1993, 40:23-40.

6. Couch SC, Daniels SR: Diet and blood pressure elevation in children and adolescents. Arch Pediatr Adolesc Med 2004, 158:418-419.

7. Couch SC, Daniels SR: Diet and blood pressure in children. Curr Opin Pediatr 2005, 17:642-647

8. Sugiyama T, Xie D, Graham-Maar RC, Inoue K, Kobayashi Y, Stettler N: Dietary and lifestyle factors associated with blood pressure among U.S. adolescents. J Adolesc Health 2007, 40:166-172.

9. Ebbeling CB, Pawlak DB, Ludwig DS: Childhood obesity: public-health crisis, common sense cure. Lancet 2002, 360:473-482.

10. Beunza JJ, Martinez-Gonzalez MA, Ebrahim S, Bes-Rastrollo M, Nunez J, Martinez JA, Alonso A: Sedentary behaviors and the risk of incident hypertension: the SUN Cohort. Am J Hypertens 2007, 20:1156-1162.

11. Brion MA, Ness AR, Davey Smith G, Leary SD: Association between body composition and blood pressure in a contemporary cohort of 9-year-old children. J Hum Hypertens 2007, 21:283-290.

12. Luepker RV, Jacobs DR, Prineas RJ, Sinaiko AR: Secular trends of blood pressure and body size in a multi-ethnic adolescent population: 1986 to 1996. J Pediatr 1999, 134:668-674.

13. Veber VP, Kazymov MS, Kopina MN, Rubanova MP, Shmat'ko DP, Zakharova lu V, Mishkina Mlu: [Age- and sex-related prevalence of overweight, arterial hypertension, hyperglycemia and their combinations]. Ter Arkh 2008, 80:76-78

14. Chiolero A, Madeleine G, Gabriel A, Burnier M, Paccaud F, Bovet P: Prevalence of elevated blood pressure and association with overweight in children of a rapidly developing country. J Hum Hypertens 2007, 21:120-127.

15. McNiece $K L$, Poffenbarger TS, Turner $\lrcorner$, Franco KD, Sorof JM, Portman RJ: Prevalence of hypertension and pre-hypertension among adolescents. J Pediatr 2007, 150:640-4, 644 e1.

16. Sorof J, Daniels S: Obesity hypertension in children: a problem of epidemic proportions. Hypertension 2002, 40:441-447.

17. Liang YJ, Xi B, Hu YH, Wang C, Liu JT, Yan YK, Xu T, Wang RQ: Trends in blood pressure and hypertension among Chinese children and adolescents: China Health and Nutrition Surveys 1991-2004. Blood Press 2011, 20:45-53.

18. Traissac P, El Ati J, Delpeuch F, Beji C, Aounallah-Skhiri H, Ben Romdhane H, Maire B: Overall vs abdominal obesity: difference in prevalence, geographic distribution and associated socio-economic factors among Tunisian women. Obesity Facts 2009, 2(Suppl 2):103.

19. Ben Romdhane H, Ben Ali S, Skhiri H, Traissac P, Bougatef S, Maire B, Delpeuch F, Achour N: Hypertension among Tunisian adults: results of the TAHINA project. Hypertens Res 2011, 198.

20. Aounallah-Skhiri H, Romdhane HB, Traissac P, Eymard-Duvernay S, Delpeuch F, Achour N, Maire B: Nutritional status of Tunisian adolescents: associated gender, environmental and socio-economic factors. Public Health Nutr 2008, 11:1306-1317.

21. National Statistics Institute of Tunisia: Results of the 2004 census:.[http:// www.ins.nat.tn/indexen.php], (accessed october 2010).

22. United Nations Development Program: Human Development Report 2005. New York: United Nations; 2005, 372.

23. Mejean C, Traissac P, Eymard-Duvernay S, El Ati J, Delpeuch F, Maire B: Influence of socio-economic and lifestyle factors on overweight and nutrition-related diseases among Tunisian migrants versus non-migrant Tunisians and French. BMC Pub Health 2007, 7:265.

24. Delpeuch F, Cornu A, Massamba JP, Traissac P, Maire B: Is body mass index sensitively related to socio-economic status and to economic adjustment? A case study from the Congo. Eur J Clin Nutr 1994, 48(Suppl 3):S141-S147.

25. El Ati J, Houti L, Farhat A, Nguyen-Than V, Eymard-Duvernay S, Beji C, Kolsteren P, Chougrani S, Gaigi S, Maire B: Development, reproducibility and validity of a physical activity frequency questionnaire in North Africa. Arab J Food Nutrition 2004, 5:148-167.
26. Ainsworth BE, Haskell WL, Whitt MC, Irwin ML, Swartz AM, Strath SJ, O'Brien WL, Bassett DR, Bassett DR Jr, Schmitz KH, Emplaincourt PO, et al: Compendium of physical activities: an update of activity codes and MET intensities. Med Sci Sports Exerc 2000, 32(Suppl 9):S498-504.

27. Haskell WL, Lee IM, Pate RR, Powell KE, Blair SN, Franklin BA, Macera CA, Heath GW, Thompson PD, Bauman A: Physical activity and public health: updated recommendation for adults from the American College of Sports Medicine and the American Heart Association. Med Sci Sports Exerc 2007, 39:1423-1434.

28. Cohen S, Kamarck T, Mermelstein R: A global measure of perceived stress. $J$ Health Soc Behav 1983, 24:385-396.

29. De Onis M, Onyango AW, Borghi E, Siyam A, Nishida C, Siekmann J: Development of a WHO growth reference for school-aged children and adolescents. Bull World Health Organ 2007, 85(9):660-667.

30. National High Blood Pressure Education Program Working Group on High Blood Pressure in Children and Adolescents: The fourth report on the diagnosis, evaluation, and treatment of high blood pressure in children and adolescents. Pediatrics 2004, 114(2 Suppl 4th Report):555-76.

31. Paradis G, Tremblay MS, Janssen I, Chiolero A, Bushnik T: Blood pressure in Canadian children and adolescents. Health Rep 2010, 21(2):15-22.

32. Falkner B: Hypertension in children and adolescents: epidemiology and natural history. Pediatr Nephrol 2010, 25:1219-1224.

33. Lauritsen JM, Bruus M, Myatt M: EpiData, a tool for validated data entry and documentation of data. Version 3.1. UK: County of Denmark and Brixton Health 2000

34. StataCorp: Stata Statistical Software/SE 11.2 College Station, TX: Stata Corporation; 2009.

35. Pall D, Katona E, Paragh G, Zrinyi M, Zatik J, Fulesdi B: [Epidemiological data of 15-18 year adolescents and the prevalence of hypertension in Debrecen. The DebrecenHypertension Study]. Orv Hetil 2005, 146:127-132.

36. Rosa ML, Fonseca VM, Oigman G, Mesquita ET: Arterial prehypertension and elevated pulse pressure in adolescents: prevalence and associated factors. Ara Bras Cardiol 2006, 87:46-53.

37. Kollias A, Antonodimitrakis P, Grammatikos E, Chatziantonakis N, Grammatikos EE, Stergiou GS: Trends in high blood pressure prevalence in Greek adolescents. J Hum Hypertens 2009, 23:385-390.

38. Andrade $H$, Antonio N, Rodrigues D, Da Silva M, Pego M, Providencia LA: High blood pressure in the pediatric age group. Rev Port Cardiol 2010, 29:413-432.

39. Drukteinis JS, Roman MJ, Fabsitz RR, Lee ET, Best LG, Russell M, Devereux RB: Cardiac and systemic hemodynamic characteristics of hypertension and prehypertension in adolescents and young adults: the Strong Heart Study. Circulation 2007, 115:221-227.

40. Al Salloum AA, El Mouzan MI, Al Herbish AS, Al Omar AA, Qurashi MM: Blood pressure standards for Saudi children and adolescents. Ann Saudi Med 2009, 29:173-8.

41. Aglony M, Acevedo M, Ambrosio G: Hypertension in adolescents. Expert Rev Cardiovasc Ther 2009, 7:1595-1603.

42. Hansen ML, Gunn PW, Kaelber DC: Underdiagnosis of hypertension in children and adolescents. Jama 2007, 298:874-879.

43. Al-Sendi AM, Shetty P, Musaiger AO, Myatt M: Relationship between body composition and blood pressure in Bahraini adolescents. Br J Nutr 2003, 90:837-844.

44. Dasgupta K, O'Loughlin J, Chen S, Karp I, Paradis G, Tremblay J, Hamet P, Pilote L: Emergence of sex differences in prevalence of high systolic blood pressure: analysis of a longitudinal adolescent cohort. Circulation 2006, 114:2663-2670.

45. Tirosh A, Afek A, Rudich A, Percik R, Gordon B, Ayalon N, Derazne E, Tzur D, Gershnabel D, Grossman E, et al: Progression of normotensive adolescents to hypertensive adults: a study of 26,980 teenagers. Hypertension 2010, 56:203-209.

46. Grigore D, Ojeda NB, Alexander BT: Sex differences in the fetal programming of hypertension. Gend Med 2008, 5(Suppl A):S121-32.

47. Kawabe H, Shibata H, Hirose H, Tsujioka M, Saito I, Saruta T: Determinants for the development of hypertension in adolescents. A 6-year follow-up. J Hypertens 2000, 18:1557-1561.

48. Eisenmann JC, Wrede J, Heelan KA: Associations between adiposity, family history of CHD and blood pressure in 3-8 year-old children. $J$ Hum Hypertens 2005, 19:675-681. 
49. Costanzi CB, Halpern R, Rech RR, Bergmann ML, Alli LR, Mattos AP: Associated factors in high blood pressure among schoolchildren in a middle size city, southern Brazil. J Pediatr (Rio J) 2009, 85:335-340.

50. Kotsis V, Stabouli S, Papakatsika S, Rizos Z, Parati G: Mechanisms of obesityinduced hypertension. Hypertens Res 2010, 33:386-393.

51. Couch SC, Saelens BE: Factors associated with pediatric hypertension in Mexico. J Am Diet Assoc 2009, 109:992-995.

52. Colin-Ramirez E, Castillo-Martinez L, Orea-Tejeda A, Villa Romero AR, Vergara Castaneda A, Asensio Lafuente E: Waist circumference and fat intake are associated with high blood pressure in Mexican children aged 8 to 10 years. J Am Diet Assoc 2009, 109:996-1003.

53. Guimaraes IC, de Almeida AM, Santos AS, Barbosa DB, Guimaraes AC: Blood pressure: effect of body mass index and of waist circumference on adolescents. Ara Bras Cardiol 2008, 90:393-399.

54. Goran Ml: Visceral fat in prepubertal children: Influence of obesity, anthropometry, ethnicity, gender, diet, and growth. Am J Hum Biol 1999, 11:201-207.

55. Lee S, Bacha F, Gungor N, Arslanian SA: Waist circumference is an independent predictor of insulin resistance in black and white youths. $J$ Pediatr 2006, 148:188-194.

56. Cornier MA, Dabelea D, Hernandez TL, Lindstrom RC, Steig AJ, Stob NR, Van Pelt RE, Wang H, Eckel RH: The metabolic syndrome. Endocr Rev 2008, 29:777-822.

57. Aounallah-Skhiri H, El Ati J, Traissac P, Ben Romdhane H, Bougatef S, Beji C, Achour N, Delpeuch F, Maire B: Evolution de la consommation alimentaire et de la corpulence des adolescents tunisiens entre 1996 et 2005. 4ème Congrès de la Société Française de Nutrition, 10-12 décembre 2009 [http://cdn.spluw3.com/files/clients/spluwR/4216/526/Docs/pages/ 1291376310_cHJvZ3JhbW1IIFNGTiAyMDA5IE1vbnRwZWxsaWVyLnBkZg==. pdf].

58. Chiolero A, Bovet P, Paradis G: Assessing secular trends in blood pressure in children and adolescents. J Hum Hypertens 2009, 23:426-427.

59. Alonso A, Beunza JJ, Delgado-Rodriguez M, Martinez JA, MartinezGonzalez MA: Low-fat dairy consumption and reduced risk of hypertension: the Seguimiento Universidad de Navarra (SUN) cohort. Am J Clin Nutr 2005, 82:972-979.

60. Pereira MA, Jacobs DR Jr, Van Horn L, Slattery ML, Kartashov Al, Ludwig DS: Dairy consumption, obesity, and the insulin resistance syndrome in young adults: the CARDIA Study. Jama 2002, 287:2081-2089.

61. Toledo E, Delgado-Rodriguez M, Estruch R, Salas-Salvado J, Corella D, Gomez-Gracia E, Fiol M, Lamuela-Raventos RM, Schroder H, Aros F, et al: Low-fat dairy products and blood pressure: follow-up of 2290 older persons at high cardiovascular risk participating in the PREDIMED study. Br J Nutr 2009, 101:59-67.

62. Aounallah-Skhiri H, Traissac P, El Ati J, Eymard-Duvernay S, Landais E, Achour $N$, et al: Nutrition transition among adolescents of a southMediterranean country: dietary patterns, association with socioeconomic factors, overweight and blood pressure. A cross-sectional study in Tunisia. Nutr J 2011, 10(1):38.

63. Chiolero A, Bovet P, Paradis G, Paccaud F: Has blood pressure increased in children in response to the obesity epidemic? Pediatrics 2007, 119:544-553.

64. Field AE, Cook NR, Gillman MW: Weight status in childhood as a predictor of becoming overweight or hypertensive in early adulthood. Obes Res 2005, 13:163-169.

65. Kim KR, Kim MK, Shin YJ, Choi BY: Relationship between the change in overweight status from childhood to adolescence and metabolic syndrome phenotypes: a 9-year retrospective study. Eur J Clin Nutr 2008, 62:748-753.

66. Andersen LB, Harro M, Sardinha LB, Froberg K, Ekelund U, Brage S, Anderssen SA: Physical activity and clustered cardiovascular risk in children: a cross-sectional study (The European Youth Heart Study). Lancet 2006, 368:299-304

67. Rodrigues AN, Perez AJ, Carletti L, Bissoli NS, Abreu GR: The association between cardiorespiratory fitness and cardiovascular risk in adolescents. J Pediatr (Rio J) 2007, 83:429-435.

68. Caputo JL, Gill DL, Tseh W, Jamurtas AZ, Morgan DW: Perceived stress and blood pressure in early adolescent children. Ann Behav Med 2000, 22:65-70.

69. Suter PM, Maire R, Holtz D, Vetter W: Relationship between self-perceived stress and blood pressure. J Hum Hypertens 1997, 11:171-176.
70. Nyklicek I, Vingerhoets JJ, Van Heck GL: Hypertension and objective and self- reported stressor exposure: a review. J Psychosom Res 1996, 40:585-601.

71. Kerr M: Prehypertension in Teens Likely to Progress. Moderately elevated blood pressure during adolescence a red flag 2006, 3(8), DOC News.

72. Chen $X$, Wang $Y$, Appel $L J, M i ~ J$ : Impacts of measurement protocols on blood pressure tracking from childhood into adulthood: a metaregression analysis. Hypertension 2008, 51:642-649.

\section{Pre-publication history}

The pre-publication history for this paper can be accessed here: http://www.biomedcentral.com/1471-2458/12/98/prepub

doi:10.1186/1471-2458-12-98

Cite this article as: Aounallah-Skhiri et al:: Blood pressure and associated factors in a North African adolescent population. a national cross-sectional study in Tunisia. BMC Public Health 2012 12:98.

\section{Submit your next manuscript to BioMed Central and take full advantage of:}

- Convenient online submission

- Thorough peer review

- No space constraints or color figure charges

- Immediate publication on acceptance

- Inclusion in PubMed, CAS, Scopus and Google Scholar

- Research which is freely available for redistribution

Submit your manuscript at www.biomedcentral.com/submit
C) Biomed Central 